\title{
Re-Os pyrite dating constrains fluid flow history in Wollaston Domain Shear Zones spatially associated with Athabasca Basin U mineralization
}

\author{
JONATHAN TOMA ${ }^{1}$, ROBERT CREASER ${ }^{2}$ AND COLIN \\ $\mathrm{CARD}^{3}$ \\ ${ }^{1}$ University of Alberta \\ ${ }^{2}$ University of Alberta, Canada \\ ${ }^{3}$ Saskatchewan Geological Survey \\ Presenting Author: toma@ualberta.ca
}

Pre-Athabasca Supergroup structures played an important role in channelizing reduced fluids into the Athabasca Basin of Saskatchewan, Canada [1]. Although the life-cycle of these structures is undoubtly long-lived - spanning 100s of Myrs or more [1], they under went a critical rheological change from a ductile to semi-brittle regime ca. 1800-1700 Ma [2]. This change allowed higher volumes of carbonic-rich fluid to pass through these long-lived shear zones and precipitate graphite and pyrite that could later serve as a reductant for uranium mineralization [1].

Underlying the eastern flanks of the Athabasca Basin are graphitic \pm pyritic shear zones hosted in Wollaston Domain basement rocks and spatially associated with some of the largest unconformity uranium deposits in the world (e.g. McArthur River and Cigar Lake). Martz et al. (2017) and others attributed the preciptation of these minerals to a carbonic-fluid flow event triggered by post-orogenic uplift and cooling that is indirectly bracketed to ca. 1770-1715 Ma.

Here we present preliminary Re-Os pyrite dates from Wollaston Domain basment shear zones straddling the eastern flanks of the Athabasca Basin. Our Re-Os pyrite dates (ca. 1750$1720 \mathrm{Ma}$ ) place the first absolute age constraints on carbonicpyritic fluid flow in Wollaston structures and confirm existing models by Martz et al. (2017) and others that this fluid flow event was synchronous with a major dewatering event following the Trans-Hudson Orogeny that was previously only constrained by Ar-Ar muscovite and Rb-Sr biotite dating (ca. 1770-1715 Ma) [4]. In addition to this, we contextualize the timing of carbonic fluid flow in eastern Pre-Athabasca Supergroup structures with similar structures in the west [5].

[1] Jefferson et al. (2007) Geological Survey of Canada, Bulletin v. 588, p. 23-67, [2] Annesley et al. (2005) Can. J. Earth Sc., v. 42, p. 573-597, [3] Martz et al. (2017) Lithos, v. 294, p. 222-2245, [4] Jeanneret et al. (2017), Precambrian Research, v. 301, p. 152-178, [5] Toma et al. (2020) Goldschmidt Abstract. 